\title{
CUSTOMER INSPIRATION: CONCEPTUALIZATION, SCALE DEVELOPMENT, AND VALIDATION
}

Tim Böttger, Postdoctoral Researcher and Lecturer, Institute of Retail Management, University of St.Gallen, Dufourstrasse 40a, 9000 St.Gallen, Switzerland, +41 71224 7193, tim.boettger@unisg.ch

Thomas Rudolph, Professor of Marketing and Director, Institute of Retail Management, University of St.Gallen, Dufourstrasse 40a, 9000 St.Gallen, Switzerland, +41 71224 2856, thomas.rudolph@unisg.ch

Heiner Evanschitzky, Professor of Marketing and Director, Aston Center for Retailing Insights (ACRI), Aston Business School, Aston Triangle, Birmingham, B4 7ET, UK, +44 1212043113 , h.evanschitzky@aston.ac.uk

Thilo Pfrang, Behavioral Science Consultant, BSC St. Gallen, Zentralstrasse 153, 8003 Zürich, Switzerland, +41 78682 5069, thilo.pfrang@bsc-sg.ch

Accepted for publication at the Journal of Marketing, 29/6/2017

\section{Acknowledgments}

The authors thank Leonard Lee, Donald R. Lehmann, Kristy R. Reynolds, David Sprott, and Gianfranco Walsh for their valuable comments on earlier versions of this manuscript. They also thank Nina Wehrli and Sarah LaCioppa for their support in the data collection. The first author gratefully acknowledges financial support from the Swiss National Science Foundation. 


\section{CUSTOMER INSPIRATION:}

\section{CONCEPTUALIZATION, SCALE DEVELOPMENT, AND VALIDATION}

Introducing customers to new ideas lies at the heart of marketing, yet surprisingly little is known about customers' state of inspiration within this domain. This article reviews prior conceptualizations of general inspiration in psychology and introduces customer inspiration as a customer's temporary motivational state that facilitates the transition from the reception of a marketing-induced idea to the intrinsic pursuit of a consumption-related goal. The authors develop and validate a two-state, 10 -item customer inspiration scale that consists of inspired-by and inspired-to states. The scale development process begins with item generation, followed by five studies: (1) scale purification and initial validation, (2) exploration of the nomological network, (3) tests for the experimental and predictive validity, (4) replication within a field experiment, and (5) assessments of generalizability and boundary conditions. Empirical results reveal sound psychometric properties of the scale, demonstrate its unique position in relation to established marketing constructs, and support experimental and predictive validity. Applying the scale in marketing practice offers a new way for firms to increase demand, motivate customers' exploration behavior, and build customer loyalty.

Keywords: inspiration; scale development; loyalty; marketing of ideas; shopping behavior 
Pinterest, which describes itself as the world's catalog of ideas, is a social website that allows consumers to browse images and products through a visual user interface, pin them to their digital boards, and share them. The website and associated app enjoy great popularity, especially among women, who account for the largest proportion of the 150 million active users (Aslam 2017). The concept behind Pinterest is that by showing products "in use" (for instance, through recipes, DIY instructions, or fashion outfits), customers would receive new ideas about consumption possibilities - possibilities they might not have been aware of and might find surprising. In doing so, Pinterest tends to stimulate customers' imaginations and broaden their mental horizons about product use. Seventy percent of Pinterest users indicate "to get inspiration on what to buy" as a reason for using the social network (Silver 2012). Subsequently, a purchase often follows as Pinterest has the highest sales conversion rate among comparable social networks, and its average order value surpasses that of competitors (Barnes and Lescault 2014). Thus, several companies (e.g., Kraft Foods, Maggi, Sephora, and Sony) use Pinterest to promote their products, inspire customers, and strengthen customer relationships (Pinterest 2017).

The above example illustrates that, first, a state of inspiration can be evoked by an external stimulus (e.g., a recipe posted to Pinterest) when customers seek and are receptive to new ideas (e.g., planning a meal). Second, inspiration involves a motivating aspect that serves as a trigger to change a routine consumption practice (e.g., creating the meal posted to Pinterest). Thus, inspiration includes the transition from the state of "being inspired by" an external factor, to a state of "being inspired to" actualize a new idea.

Because inspiring customers lies at the heart of marketing, the study of customers' state of inspiration offers the potential to advance marketing theory. Prior literature suggests that customers may derive benefits from enriching, inspirational brands (Park, Eisingerich, and Park 
2013) or inspiring shopping experiences (Lee and Böttger, in press), and may experience transcendent moments during consumption (Arnould and Price 1993; Celsi, Rose, and Leigh 1993). However, inspiration has rarely been defined, nor has its construct validity been examined within the marketing domain. As a result, the current literature on inspiration in marketing is largely atheoretical and lacks a common understanding of the construct of inspiration. A more thorough understanding of customer inspiration is required in order to help marketers effectively and efficiently influence consumer response to their market offerings.

Moreover, marketing research has rarely assessed inspiration empirically and lacks a standardized measure. A domain-specific measure is necessary, as broad measures tend to be poor predictors of specific outcomes (Ajzen 1987). Furthermore, because inspiration in marketing involves different goals, recipients, and sources of inspiration, the marketing domain seems sufficiently different from prior areas of inspiration research (e.g., general psychology, education, sports, creativity) to warrant a domain-specific conceptualization and measurement (Kassarjian 1971; see also Aaker 1997; Bearden, Netemeyer, and Teel 1989). In the absence of a standardized scale, some researchers have resorted to constructing ad-hoc domain-specific scales to measure inspiration in marketing (e.g., Liang, Chen, and Lei 2016). Using a standardized scale is preferred to this practice because its reliability and validity are established, and its use enables comparisons across studies (Goldsmith and Hofacker 1991).

Our research aims to contribute to marketing literature by (a) conceptualizing and examining inspiration within a marketing context, and (b) developing and validating a scale to improve measurement of inspiration in marketing. We propose that the inspiration literature in psychology (e.g., Thrash and Elliot 2003, 2004) is transferable to the marketing domain and adds a new perspective to existing marketing phenomena. Responding to calls for contextualization of 
inspiration (Thrash et al. 2014), we propose such a definition of inspiration for the marketing context that is also compatible with the wider inspiration literature. We show empirically that inspiration uniquely predicts relevant marketing outcomes such as exploration and purchase behavior. We also test whether our domain-specific scale improves predictions of such outcomes over a general measure of inspiration. Finally, we provide evidence for unique manipulations and boundary conditions that derive from an inspiration perspective on marketing.

The remainder of our manuscript is structured as follows. First, we review the emerging inspiration literature and provide a marketing-specific definition of customer inspiration. Based on that definition, we develop and validate a two-state scale for customer inspiration. Our empirical scale development and validation process consists of an extensive item generation, and five empirical studies that place customer inspiration in a nomological network of related constructs and that confirm experimental and predictive validity. Finally, we discuss how customer inspiration may provide a new way for firms to increase demand, foster customers' exploration behavior, and strengthen customer loyalty.

\section{Theoretical Background}

\section{Customer Inspiration as a Motivational State}

Motivation, long the object of scientific inquiry, has been described as the psychological force that enables goal-directed behavior (Lewin 1935). As such, motivation consists of activation and intention (Ryan and Deci 2000). It includes both the energization to strive for existing goals and the setting of new goals (Gollwitzer 1990). Moreover, motivation can be classified as either intrinsic or extrinsic in nature. Self-determination theory (Ryan and Deci 
2000) posits that intrinsic motivation refers to carrying out an activity for the inherent satisfaction of the activity itself, and that it is driven by a desire for autonomy, competence, and relatedness. Extrinsic motivation, in contrast, is powered by the desire to attain a separable outcome.

Inspiration is a particular type of intrinsic motivational state that is characterized by a strong epistemic component. For example, Olyenick et al. (2014, p. 1) define inspiration as a "motivational state that compels individuals to bring ideas into fruition" (for an extended literature review, see the Web Appendix). Like other intrinsic motivations, inspiration focuses on incentives that are inherent to the task, and results in autonomous behaviors (Ryan and Deci 2000). However, inspiration is a specific intrinsic motivation because it is evoked by an external source and is connected to the realization of new ideas (Thrash and Elliot 2003). As a temporary state rather than a more permanent trait, inspiration thus bridges the gap between the deliberation phase (i.e., goal setting) and the implementation phase (i.e., goal striving) of goal pursuit (Gollwitzer 1990).

Recent general conceptualizations in social psychology seem to coalesce around three complementary frameworks of inspiration (see Table 1). First, the tripartite conceptualization (Thrash and Elliot 2003) describes the three key characteristics of inspiration: evocation, transcendence, and motivation. Evocation refers to the fact that inspiration is spontaneously evoked by an external source rather than being willingly initiated by the recipient.

Transcendence describes a feeling of positivity, clarity, and self-enhancement, since inspiration involves the realization and appreciation of a new idea. Inspiration then leads to approach motivation (Elliot and Thrash 2002), such that a person would feel compelled to actualize the new idea. Second, the component process conceptualization (Thrash and Elliot 2004) proposes 
that an episode of inspiration involves two distinct components: an activation state that is captured in the notion of being inspired by something (i.e., evocation and transcendence), and an intention state that can be understood as being inspired to act or to do something (i.e., motivation). Finally, the transmission model of inspiration (Thrash, Maruskin, et al. 2010) describes the function of inspiration as the facilitation of a transition between these two states.

\section{--- Insert Table 1 about here ---}

General conceptualizations of inspiration as outlined above draw on the core commonalities across streams of literature and are, therefore, valuable to ease cross-talk between disciplines. However, they are often too broad to be directly applied to a specific context, such as marketing, and tend to be poor predictors of specific outcomes (Ajzen 1987; Kassarjian 1971). Responding to calls for a better contextualization of inspiration for specific domains (Thrash et al. 2014), we aim to provide a conceptualization that encompasses the essence of customer inspiration while still offering consistency with other literature. In the marketing context, therefore, we define customer inspiration as a customer's temporary motivational state that facilitates the transition from the reception of a marketing-induced idea to the intrinsic pursuit of a consumption-related goal.

While this definition, in the main, is based on the transmission model of general inspiration (Thrash, Maruskin, et al. 2010), it is also specific to the marketing domain. First, we focus on customers as the recipients of inspiration, in contrast to the literature on general inspiration that mainly concerns the behavior of patients or students (e.g., Hart 1998; Hymer 1990; Thrash and Elliot 2004). Second, while prior research examines sources of inspiration such as role models (Lockwood and Kunda 1999), examples of work mastery (Thrash, Elliot, et al. 2010), or poetry (Thrash et al. 2016), our definition aims at the stimulation of ideas prompted by a conscious 
marketing effort. Finally, while general inspiration is mostly concerned with inspiration to reach personal goals, such as achievement, power, work mastery, or creativity (e.g., Thrash, Maruskin, et al. 2010; Thrash and Elliot 2004), our definition focuses on consumption-related goals such as purchasing, donating, or engaging with a brand.

\section{Components of Customer Inspiration}

As a motivational state, customer inspiration consists of both an activation and an intention component (Ryan and Deci 2000; Thrash and Elliot 2004). Accordingly, we propose that the state of customer inspiration can be decomposed into an epistemic activation component (the state of "inspired by") and an intention component (the state of "inspired to"). Both components are necessary to create a full episode of inspiration, yet they represent distinct states within this process (Hart 1998; Thrash et al. 2014; Thrash and Elliot 2004). Consequently, our conceptual framework illustrates customer inspiration as a second-order construct that is composed of both an inspired-by state and an inspired-to state (see Figure 1).

\section{--- Insert Figure 1 about here ---}

The inspired-by activation state relates to the reception of a marketing-induced new idea (i.e., evocation) and the shift in customer awareness toward new possibilities (i.e., transcendence). In daily experiences, inspiration is often described as a "light bulb," "Aha!," or "Eureka!" moment of sudden realization and insight (Hart 1998; Oleynick et al. 2014; Thrash et al. 2016). In a marketing context, customers often receive such new ideas through marketers' efforts to promote their offerings. As a result, customers may then experience transcendence toward a new state of mind. Customers sometimes describe this transcendence as the stimulation of imagination or the broadening of mental horizons. In its extreme form, transcendence can lead to self-transformation (e.g., Arnould and Price 1993; Kozinets 2002). 
The inspired-to state relates to the intrinsic pursuit of a consumption-related goal. In this state, customers experience an urge to actualize the new idea (e.g., by purchasing and using a product) rather than to extend or replicate it (Thrash et al. 2014). Congruous with the literature on general inspiration (Thrash and Elliot 2003), we understand this state to be an approach motivation, rather than an avoidance motivation (Elliot and Thrash 2002).

Based on the transmission model of inspiration (Thrash, Maruskin, et al. 2010), we propose that customers make a transition from the state of being inspired by a marketing-elicited idea to the state of being inspired to actualize this idea. The two states are causally linked, such that inspired-by mediates the effect of marketing stimuli on inspired-to. This conceptualization is also in line with Gollwitzer's (1990) mindset theory of action phases, which divides the decisionmaking process into a pre-decision phase of deliberation and a post-decision phase of implementation. While the inspired-by state is part of the deliberation phase, the inspired-to state marks the transition to the implementation phase. Therefore, inspiration adds an important in situ measure to study customer motivation and the experiences along the customer journey (Lee and Ariely 2006; Lemon and Verhoef 2016).

\section{Related Marketing Constructs and Delineation}

Having conceptualized customer inspiration as a motivational state with two distinct component states, we broaden our conceptual perspective to address the unique position of customer inspiration in its nomological network of related marketing constructs (see Figure 1). Towards this objective, we classify established constructs as either antecedents or consequences of customer inspiration (see Web Appendix for an overview).

Antecedents. The emergence of inspiration depends both on the presence of an inspiring source as well as on the characteristics of the recipient of inspiration (Thrash and Elliot 2003; 
2004). In marketing, customer inspiration may result from print ads, novel product assortments, in-store presentations, personalized messages, and many other sources in the consumption environment. While the list of potential sources is vast and constantly expanding due to new technologies, we propose that most inspiring sources share three source characteristics. These include the provision of inspirational content (i.e., including a new idea), appeals to use one's imagination, and elicitation of an approach rather than an avoidance motivation.

At the same time, individual characteristics such as the recipient's openness to inspiration also play an important part in predicting the frequency and intensity of inspirational experiences (Thrash and Elliot 2003). In a consumption context, this openness to inspiration is, for example, reflected in the notion of idea shopping, which describes the hedonic motivation to go shopping with the intent to see new products, innovations, trends, and fashions (Arnold and Reynolds 2003; Evanschitzky et al. 2014). We propose that customers with an idea-shopping motive are more receptive to inspiration and thus experience stronger inspiration than do other customers when they are exposed to the same source of inspiration.

Consequences. We propose that customer inspiration leads to behavioral, emotional, and attitudinal consequences. From a behavioral perspective, inspiration leads to an intrinsic motivation to actualize a new idea (Thrash, Maruskin, et al. 2010), and the resulting behavior depends on the content of this new idea (e.g., the message of an advertisement). By definition, marketing concerns creating, communicating, delivering, and exchanging offerings (American Marketing Association 2013). Therefore, we expect that inspiration in this domain will most often lead to the impulsive purchase of unplanned products or services, exploration of the offering, or engagement with the marketing firm in some other meaningful way (e.g., Brodie et al. 2011; Pansari and Kumar 2016; Rook and Fisher 1995). 
Additionally, customer inspiration may lead to emotional consequences. Most prominently, positive affect is one of the two dominant dimensions of mood, and has been found to correlate strongly with inspiration in a variety of settings (Thrash and Elliot 2003, 2004). Although prior research suggests that positive affect is conceptually and empirically distinct from inspiration (Oleynick et al. 2014), the state of inspriation can induce positive affect (Thrash, Elliot, et al. 2010). Furthermore, customer inspiration may also trigger the emotional response of delight, which combines high pleasure (joy, elation) with a feeling of surprise (Finn 2005; Oliver, Rust, and Varki 1997). Delight does not necessarily contain a transcendent component like inspiration, but the sudden realization of a new idea may lead to surprise and elation that is manifested in feeling delighted. Finally, taking a broader perspective, customer inspiration may lead to transcendent customer experiences (TCEs) that include peak and flow experiences in a consumption context (Schouten, McAlexander, and Koenig 2007). Although TCEs represent a much larger class of phenomena that also includes non-inspiring experiences, many share with inspiration the characteristic of transcendence (i.e., positivity, clarity, and self-transformation). For instance, many, but not all, peak experiences may have within them the motor of inspiration (Hart 1998). Hence, we propose that being inspired by a marketing-induced idea may lead to emotional consequences such as positive affect, delight, and transcendent customer experiences.

More distally, customer inspiration can also have attitudinal consequences-enduring evaluative judgments that are more stable than emotions. For instance, Park et al. (2013) propose that companies that offer inspiring and enriching experiences may benefit from increasing brand attachment. Similarly, we propose that customer inspiration can increase customer loyalty, because it creates a feeling of connectedness with the marketing firm (Hart 1998). Furthermore, intrinsic motivation has been shown to lead to higher levels of satisfaction (Ryan and Deci 
2000), and customer inspiration as an intrinsic motivational state may thus lead to customer satisfaction in a marketing context. While these attitudinal consequences may seem more remote from customer inspiration, we propose that they are influenced positively either directly by customer inspiration or indirectly by its emotional and behavioral consequences.

These many and disparate components come together to support an essential point - that while there are several established marketing constructs that relate to customer inspiration, none seems to capture this intrinsic motivational state in its entirety. In order to stimulate research on this unique construct, we develop a standardized domain-specific scale for the measurement of customer inspiration. We test its validity and reliability in a variety of settings and show its usefulness to improve predictions over more general measures of inspiration in prior literature (Thrash and Elliot 2003, 2004).

\section{Scale Development and Validation Process}

To develop a scale for measuring customer inspiration, we followed established scale construction recommendations (Churchill 1979; Gerbing and Anderson 1988) and prior scaledevelopment studies (e.g., Bearden, Netemeyer, and Teel 1989; Nenkov, Inman, and Hulland 2008; Tian, Bearden, and Hunter 2001). Our initial item generation is followed by five studies, involving (1) scale purification and initial validation, (2) an exploration of the nomological network, (3) tests for the experimental and predictive validity, (4) a replication of predictive validity within a field experiment, and (5) an assessment of generalizability and a boundary condition. We analyzed both qualitative and quantitative data gathered from marketing academics, top managers, students, and an online panel, as well as shopper field data. 


\section{Item Generation}

For the item generation, we aimed at developing a broad set of items that would encompass all potential aspects of the inspired-by and inspired-to states of customer inspiration (Churchill 1979). We created ninety-three potential scale items to measure customer inspiration, using as a basis both our literature review and a short qualitative survey of 918 shoppers ${ }^{1}$. A panel of 10 experts evaluated each statement for content and face validity. In order to ensure that our items were relevant for marketing research as well as for marketing practice, the panel included five senior marketing academics from peer universities, and five top managers who were either CEOs or CMOs within their organizations. These experts rated each item using a 5-point scale with a range from "Very bad fit (1)" to "Very good fit (5)." Furthermore, each expert selected five items with the best overall construct fit. Scores for each item were averaged separately for managers and academics in order to calculate a managerial score $\left(\mathrm{M}_{\text {manager }}=3.07, \mathrm{SD}=.45\right)$ and an academic score $\left(\mathrm{M}_{\text {academic }}=3.34, \mathrm{SD}=.75\right)^{2}$. We retained items if both the academic score and the managerial score were favorable (above 3.0) or if at least one of the experts selected an item as one of the five best-fitting. This procedure shortened the list to 43 items.

To further increase content and face validity, the remaining items were subject to two sorting tasks. In the first sorting task, a sample of 33 participants (52\% male, median age 24) from an online panel read a short explanation of the customer inspiration construct and then organized the items by similarity, creating as many categories as they deemed appropriate. From this, one item was classified as inappropriate and 10 items were refined. In the second sorting task, a separate sample of 25 raters ( $52 \%$ female, median age 34$)$ with prior experience in categorization tasks assessed the remaining 42 items. Participants were given a short description of customer inspiration and its two conceptual states (inspired by and inspired to) and were then 
asked to assign each item to one of the two states, or to mark it as unrelated to any state. Retaining only items that had been assigned to their respective a priori category by at least $60 \%$ of the judges, we subsequently eliminated five items. At the end of this process, 37 potential scale items remained, of which 26 items measured the inspired-by component of customer inspiration, and 11 items measured the inspired-to component.

\section{Study 1: Scale Purification and Initial Validation}

Following Bearden, Netemeyer, and Teel (1989), we performed separate item analysis for the remaining 37 statements, including confirmatory factor analyses, tests for discriminant validity, and a known group comparison.

Participants and procedure. We engaged 287 undergraduate students to participate in a study, in exchange for a chance to win university-branded clothing. Participants were randomly assigned to one of two conditions - labeled neutral and inspired. Participants in the neutral condition were asked to remember their most recent shopping experience, whereas participants in the inspired condition were asked to remember their most recent inspiring shopping experience. Both groups were asked to briefly describe their shopping experiences and then rate the 37 potential scale items from "strongly disagree (1)" to "strongly agree (7)" in individually randomized order. An instructional check ensured that participants read each item carefully. Thirty participants failed this check, leaving a final sample of 257 participants (57\% male, median age 22) for further analysis.

Scale purification. Following prior literature (e.g., Arnold and Reynolds 2003), we used iterative confirmatory factor analyses (CFA) to assess the reliability and convergent validity of the proposed scale, as well as to consolidate similar items. First, we specified a two-factorial confirmatory model with all 37 potential items. The model fit indices of this initial model $(\mathrm{CFI}=$ 
$.85 ; \mathrm{TLI}=.84 ; \mathrm{RMSEA}=.092 ; \mathrm{SRMR}=.055)$ missed acceptable thresholds $(\mathrm{Hu}$ and Bentler 1999). In order to refine the scale, we then inspected items with low individual reliabilities $(<.50$; Bagozzi and Yi 1988) for their conceptual fit and domain representativeness. On this basis, we eliminated eight items and performed a CFA with the remaining 29 items. Since the resulting model fit was still below acceptable thresholds, we inspected the modification indices (Arnold and Reynolds 2003). Items identified as suitable for exclusion were those that either accounted for a single high modification index $(>30)$ or were involved in ten or more significant indices $(>$ 3.84). After inspecting each of these items and consolidating those that appeared to belong to the same facet of customer inspiration, we eliminated an additional 11 items. The remaining 18 items (12 for inspired-by; 6 for inspired-to) were again subjected to a CFA, which revealed acceptable model fit $(\mathrm{CFI}=.96 ; \mathrm{TLI}=.95 ; \mathrm{RMSEA}=.069 ; \mathrm{SRMR}=.048$; see Web Appendix section 18-Item Long Customer Inspiration Scale).

While the 18-item scale demonstrates acceptable measurement properties, it may be too lengthy for practitioner use. A shorter scale would allow constructs to be added to surveys, reduce demand effects, and prevent practitioners from reducing the number of scale items based on a heuristic (Richins 2004). Following established guidelines for scale shortening (Richins 2004; Stanton et al. 2002), we inspected the remaining 18 items, considering their internal consistency as well as face validity and domain representativeness. Based on these considerations, we selected 10 items with high loadings $(>.70)$ that captured the essence of the inspired-by (five items) and inspired-to (five items) components of customer inspiration. This final scale was subjected to a CFA, which revealed very good model fit indices (CFI = .99; TLI $=.99 ; \mathrm{RMSEA}=.044 ; \mathrm{SRMR}=.029)$. All items loaded significantly on their designated constructs, with standardized loadings ranging from .72 to .86 , individual item reliabilities 
ranging from .52 to .74 , and corrected item-total correlations ranging from .71 to .83 .

Furthermore, coefficient alpha, average variance extracted (AVE), and composite reliability $(\mathrm{CR})$ for inspired-by $(\alpha=.89 ; \mathrm{AVE}=.62 ; \mathrm{CR}=.89)$ and inspired-to $(\alpha=.92 ; \mathrm{AVE}=.70 ; \mathrm{CR}=$ .92) were above recommended thresholds (Fornell and Larcker 1981), providing evidence of convergent validity. Table 2, column Study 1, provides detailed results and the final scale.

\section{--- Insert Table 2 about here ---}

Discriminant validity. We ran two tests to assess the discriminant validity of the two inspiration states. First, the average variance extracted for both inspired-by $(\mathrm{AVE}=.62)$ and inspired-to $(\mathrm{AVE}=.70)$ exceeded the squared correlation between the constructs of $\mathrm{r}^{2}=.57$ (Fornell and Larcker 1981). Second, the two-factor model was contrasted with a one-factor model in which all items loaded on one latent variable (Burnkrant and Page 1982). Chi-square statistics indicated a significantly better fit for the baseline two-factor model $\left(\Delta \chi^{2}(1)=221.84, p\right.$ $<.001)$, supporting discriminant validity.

Known group comparison. In order to further assess the content validity of the scale, we performed a known group comparison (Churchill, 1979; Tian, Bearden, and Hunter 2001) based on the two conditions of our study. We anticipated that participants who described their most recent inspiring shopping experience (inspiration condition) would score significantly higher on our scale than those who simply described their most recent shopping experience (neutral condition). For this analysis, we averaged the items on both sub-scales for the individual participants, so that each of the resulting scale scores would range from 1 to 7 . In line with our expectations, participants in the inspiration condition scored significantly higher than those in the neutral condition on both inspired-by $\left(\mathrm{M}_{\text {inspired }}=4.37, \mathrm{M}_{\text {neutral }}=2.35, \mathrm{t}(255)=12.82, p<.001\right)$ 
and inspired-to subscales $\left(\mathrm{M}_{\text {inspired }}=5.44, \mathrm{M}_{\text {neutral }}=3.58, \mathrm{t}(255)=10.50, p<.001\right)$. Together, these results support the reliability and content validity of the proposed scale.

\section{Study 2: Discriminant Validity and Nomological Net}

Our objective for the second study was twofold. First, we sought to validate the measurement properties of the customer inspiration scale in a real shopping situation, using a wide range of shoppers from various retail industries. Second, we intended to test the discriminant validity and unique position of customer inspiration within the nomological network of related marketing constructs. As depicted in our conceptual framework, we expect established marketing constructs to relate to customer inspiration either as antecedents or as consequences. To test our predictions, we include measures for one antecedent (i.e., idea shopping), one behavioral consequence (i.e., impulse buying), three emotional consequences (i.e., positive affect, delight, and transcendent customer experiences), and two attitudinal consequences (i.e., customer satisfaction, and customer loyalty). Further details on each of these constructs and their relation to customer inspiration are available in the Web Appendix.

Because inspired-by and inspired-to belong to the same second-order construct-customer inspiration - we expect both states to correlate strongly with all related antecedents and consequences. However, we also predict differences in the relative strength of the correlations with its related constructs. Since the inspired-by component of inspiration relates to transcendence and evocation (Thrash and Elliot 2004), we expect it to correlate more strongly with emotional consequences (e.g., delight, TCEs, and positive affect). In contrast, the inspiredto component is intentional and may relate more strongly to behavioral consequences to actualize an idea (i.e., impulse buying). 
Data collection and measures. Trained students administered questionnaires to 425 shoppers (52.7 percent female, median age 31) as they exited stores located in malls or on popular shopping streets. The questionnaire contained the proposed 10-item customer inspiration scale, along with scales for the theoretically related constructs. Replicating the 10 -item customer inspiration scale from Study 1 resulted in an acceptable overall fit $(\mathrm{CFI}=.95 ; \mathrm{TLI}=.93$; RMSEA $=.10 ;$ SRMR $=.045)^{3}$. All items loaded significantly on their hypothesized constructs, with standardized loadings above .67 (Table 2, column Study 2). Both factors show high CRs (inspired by: .87; inspired to: .93) and AVEs (inspired by: .58; inspired to: .71), indicating convergent validity (Bagozzi and Yi 1988).

Discriminant validity. We assessed whether the two customer inspiration components are empirically distinct from the seven related marketing constructs. First, we compared the correlation between all seven constructs and the two states of customer inspiration to their AVEs, for a total of 14 comparisons (Fornell and Larcker 1981). All correlations with the inspired-by and inspired-to states were smaller than the square root of the AVEs for each construct (see the Web Appendix for further details). Further, combining any related construct with either of the two customer inspiration components significantly decreased overall model fit $\left(\Delta \chi^{2}(8)>211.73\right.$, ps $<.001$ ), indicating discriminant validity (Burnkrant and Page 1982).

Nomological validity. To test nomological validity, we first examined how the customer inspiration states correlate with their related marketing constructs (Nenkov, Inman, and Hulland 2008). For each related construct, Table 3 reports the measured relationships with the two states of customer inspiration. Importantly, all conceptually related constructs correlated significantly, and in the expected direction, with the inspired-by and inspired-to components of customer inspiration, showing correlations ranging from .16 to .57 . 


\section{--- Insert Table 3 about here ---}

We then used the Hotelling-William test (Steiger 1980) to assess differences in the relative strength of correlations between the measured constructs and the two states of customer inspiration. In support of our predictions, the emotional consequences delight and transcendent customer experiences correlated significantly more strongly with the inspired-by activation component, whereas impulse buying had a significantly stronger correlation with the inspired-to intention component $(p \mathrm{~s}<.05)$. We did not find initial support regarding positive affect, which related strongly to both inspired-by and inspired-to. While later experiments (Studies 3a and 4) support the hypothesized relative difference, this result could hint at a role of affect as a facilitator in decision-making. Overall, our findings support the nomological validity of the customer inspiration construct.

\section{Study 3a: Experimental and Predictive Validity}

This study extends the assessment of the proposed customer inspiration scale by providing evidence for its experimental and predictive validity in an online shopping context. We test the experimental validity by manipulating two antecedents to customer inspiration: inspirational content and idea shopping motivation. In line with our conceptualization, we propose that inspiration is a function of both the inspirational source and of the individual who is the recipient of inspiration. Thus, we manipulate not only the inspirational content of the environment (i.e., the source), but also the motivation of the customer (i.e., the individual) to search for ideas.

Our study used recipe suggestions to manipulate the inspirational content of an experimental online grocery shop, and to evoke new ideas about possible product combinations. Recipes represent one of the most popular categories on Pinterest, and such companies as Kraft Foods and Maggi have successfully used recipes to inspire customers with new ideas (Pinterest 2017). 
We therefore hypothesize that an online grocery shop that includes recipes will be more inspiring than an otherwise identical shop without recipes.

Moreover, we manipulate idea shopping motivation — the extent to which participants actively search for new ideas in an online shop. In line with our conceptualization, we expect that stimulating the motivation to look for inspiration in a shopping environment will increase openness toward inspiring stimuli and, thus, will facilitate customer inspiration. Thus, we hypothesize that idea shopping motivation will amplify the effect of inspirational content (i.e., recipes) on customer inspiration.

In line with our conceptualization of customer inspiration (Figure 1), we expect that customers are first inspired by the manipulations of inspirational content and idea shopping, which then leads to being inspired to purchase or explore products. More formally, we hypothesize that the "inspirational content $\mathrm{x}$ idea shopping" interaction has a direct effect on inspired-by, and has an indirect effect on inspired-to. We, therefore, test a mediated moderation model for the two states of customer inspiration (see Figure 1).

Finally, we aim to provide evidence for the predictive validity of customer inspiration by assessing whether the proposed scale can improve predictions of exploration behavior and purchase intentions. As discussed, we propose that customer inspiration leads to the intrinsic pursuit of a consumption-related goal. In a shopping environment, this pursuit may manifest itself in a willingness to purchase a product or to explore similar product alternatives. Therefore, we assessed participants' purchase intentions, and gauged their exploration behavior by measuring (1) the number of clicks in the online store, (2) the duration of the shopping trip, and (3) the number of products viewed. As a baseline for our comparison, we use established marketing constructs that relate to either antecedents or the immediate emotional and behavioral 
consequences of customer inspiration (see the Web Appendix). We also include a general inspiration measure (Thrash and Elliot 2004) as part of this baseline to test the convergent validity of the customer inspiration states and the need for a contextualized scale.

Participants and procedure. Our experiment uses a 2 (inspirational content: high vs. low) x 2 (idea shopping: high vs. low) between-subjects design. To manipulate inspirational content, we programmed two versions of a fully functional online store. First, we sampled 4,934 product descriptions from the online grocery seller FreshDirect- organized into 12 main categories and 200 subcategories. Each product display included a photo and name of the item, with package size and price information. This base store design represented a low inspirational content condition. For the store in the high inspirational content condition, we additionally included 104 of the most popular recipes from the website allrecipes.com. Recipes were included as a separate category, with four subcategories ("Main Dish," "Healthy Recipes," "Quick and Easy," and "Salad"). In the low inspirational content condition, the front page featured 12 randomly selected products, while the high inspirational content condition featured 12 randomly selected recipes.

We manipulated the level of idea shopping by asking participants to imagine that they were planning a dinner party for close friends that would take place in a few days. In the low idea shopping condition we asked that, before going to the online store, participants should think about a meal that their friends would enjoy. These participants, therefore, would have already formed a concrete idea before they accessed the store. In the high idea shopping condition, we asked participants to visit the online store and look inside the store for ideas about a meal, expecting that this group of participants would be more open to inspiration within the store. We instructed both groups to explore the store and to add any products to their shopping cart that they might be interested in. 
We recruited 230 U.S.-consumers (52\% female, median age 31.5$)$ from an online panel to take part in this study. Each participant was randomly assigned to one of the four experimental conditions. First, participants created an account with the online store, using a dedicated page. This enabled us to monitor their behavior throughout the experiment unobtrusively. For each participant, we recorded the number of clicks in the online store, the number of products viewed, and the total shopping duration. After participants had finished shopping, they indicated their purchase likelihood on a 7-point scale ("Not likely at all (1)" to "Extremely likely (7)"), and answered a questionnaire that included measures of customer inspiration and related constructs.

Measures. To measure customer inspiration, we used the proposed two-component 10-item scale. Confirmatory factor analysis produced an acceptable overall fit $(\mathrm{CFI}=.95 ; \mathrm{TLI}=.94$; RMSEA $=.12 ;$ SRMR $=.040)$. Both states showed high item loadings, composite reliabilities, and AVEs (Table 2, column Study 3a). In line with previous results, the inspired-by and inspired-to states of customer inspiration were significantly correlated to all their theoretically related constructs, with correlations ranging from .32 to .74 (Table 3, column Study 3a). Importantly, both customer inspiration states also had high correlations with the general inspiration state ( $\left.\mathrm{r}_{\mathrm{by}}=.73, \mathrm{r}_{\mathrm{to}}=.65, \mathrm{ps}_{\mathbf{s}}<.001\right)$, indicating convergent validity. In support of discriminant validity, the correlations of all related constructs with the two customer inspiration states were smaller than the square root of the AVEs, and combining any two constructs significantly decreased the overall model fit $\left(\Delta \chi^{2}(9)>228.64, p s<.001\right)$. All scales showed high reliabilities and item loadings (for further details, see the Web Appendix).

Manipulation checks. Participants in the high idea shopping condition indicated a greater level of idea shopping motivation $($ MHighidea $=4.44)$ than those in the low idea shopping condition $\left(\mathrm{M}_{\text {LowIdea }}=3.89, \mathrm{~F}(1,228)=6.26, p<.05\right)$. As an attentional manipulation check, we also asked 
all participants whether they had noticed recipes on the online store. As expected, $81.8 \%$ of participants in the high inspirational content conditions noticed the recipes, while only $5.8 \%$ of participants in the low conditions thought they had seen recipes $\left(\right.$ Wald $\left.\chi^{2}(1)=86.30, p<.001\right)$.

Effects on inspired-by. The scores for inspired-by were submitted to a 2 (inspirational content: high vs. low) x 2 (idea shopping: high vs. low) ANOVA. The analysis revealed a significant main effect of inspirational content $(\mathrm{F}(1,226)=8.40, p<.01)$, as well as a marginally significant interaction between inspirational content and idea shopping $(\mathrm{F}(1,226)=3.20, p=$ .08). We used planned contrast to interpret these results. As predicted, for participants in the high idea shopping condition, inspired-by was significantly higher in the high inspirational content condition $($ MHighISM-HighContent $=4.99)$ than in the low inspirational content condition (MHighISMLowContent $=4.06, t(226)=3.39, p<.001)$. In contrast, the low idea shopping condition revealed no significant difference between the high and low inspirational content conditions (MLowISMHighContent $\left.=4.69, M_{\text {LowISM-LowContent }}=4.47, t(226)=.77, p=.44\right)$, supporting our predictions and the experimental validity of the proposed construct.

Effects on inspired-to. In line with our conceptualization of customer inspiration, we expected the inspired-by component to influence the inspired-to component (see Figure 1). Therefore, we followed the general path analytic framework (Edwards and Lambert 2007) using a bootstrap procedure with 1,000 samples to test a mediated moderation of the "inspirational content x idea shopping" interaction on inspired-to via inspired-by. Our analysis confirmed an anticipated indirect effect of inspirational content on inspired-to via inspired-by $\left(B_{\text {HighIdea-Indirect }}=\right.$ $.69,95 \% \mathrm{CI}=[.29,1.16], p<.001)$ for participants in the high idea shopping condition. In contrast, there was no indirect effect in the low idea shopping condition (B BowIdea-Indirect $=.16$, 
$95 \% \mathrm{CI}=[-.24, .58], p=.46)$. There were no significant remaining direct effects, supporting a fully mediated moderation (see Table 4 for full results).

\section{--- Insert Table 4 about here ---}

Predictive validity. In order to test the predictive validity of the proposed scale for customer inspiration, we analyzed whether the two states of inspired-by and inspired-to could explain variance in purchase intentions and behavioral outcomes, beyond the predictive power of general inspiration and established correlates. We excluded sixteen participants due to technical difficulties with the cookies-based recoding mechanism, leaving a sample size of 214 participants for further analysis. We employed a multivariate analysis of covariance (MANCOVA) to account for the relationships between the dependent measures. Using Pillai's trace, this analysis revealed significant effects of inspired-by $(\mathrm{V}=.06, \mathrm{~F}(4,202)=3.24, p<.05)$ and inspired-to $(\mathrm{V}=.08, \mathrm{~F}(4,202)=4.29, p<.01)$ on the number of clicks, shopping duration, products viewed, and purchase intentions (see Table 5). We used separate hierarchical regressions to follow up on this omnibus analysis. For each dependent variable, we first specified a generalized linear model, and included only the baseline constructs. Because the number of products and number of clicks are count variables, we specified generalized linear models that assumed a Poisson distribution of these dependent variables. We assumed a log-normal distribution for the duration of time in the shop, since it is left censored at zero and positively skewed. Finally, purchase intention was assumed to have a normal distribution. We then compared these baseline models to models that also included our measures for inspired-by and inspired-to. Detailed regression results are reported in Table 5. 
Findings indicate that the inclusion of the inspired-by and inspired-to states improved the prediction of all of these models, as evidenced by a significant improvement in $\mathrm{R}^{2}$ ( $p \mathrm{~s}<.05$; see Table 5). Specifically, inspired-by significantly predicted the number of clicks $\left(\mathrm{B}_{\mathrm{By}}=.11, \mathrm{SE}=\right.$ $.02, p<.001)$, shopping duration $\left(\mathrm{B}_{\mathrm{By}}=.26, \mathrm{SE}=.11, p<.05\right)$, and purchase intentions $\left(\mathrm{B}_{\mathrm{By}}=\right.$ $.25, \mathrm{SE}=.11, p<.05)$. The inspired-to component predicted the number of clicks $\left(\mathrm{B}_{\mathrm{To}}=.05, \mathrm{SE}\right.$ $=.01, p<.001)$, number of products viewed $\left(\mathrm{B}_{\mathrm{To}}=.11, \mathrm{SE}=.04, p<.05\right)$, and purchase intentions $\left(\mathrm{B}_{\mathrm{To}}=.30, \mathrm{SE}=.08, p<.001\right)$. Together, the results suggest that customer inspiration can significantly improve marketing managers' prediction of relevant outcomes, such as purchase intentions and exploration behavior.

In further interpretation of these results, we note that inspired-by tends to explain general exploration behavior (e.g., duration of shopping trip), while inspired-to predicts more productspecific exploration behavior (e.g., products viewed). As discussed, we posit that inspired-by is part of the deliberation phase of the decision journey, while inspired-to marks the transition to the implementation phase of decision making (Gollwitzer 1990). We therefore speculate that customers who are inspired by the recipes without being inspired to make a concrete purchase may still be in the deliberation phase and, hence, are contemplating whether to actualize their new ideas. In contrast, customers who are inspired to make a purchase may already be in the implementation phase and, thus, may focus more on how to actualize their new ideas.

\section{Study 3b: Field Replication}

In order to provide further evidence of the experimental and predictive validity of customer inspiration, we replicated our findings from Study $3 \mathrm{a}$ in a field setting. In collaboration with a national grocery chain, we used an in-store promotion for organic products to test the effect of inspirational content on shoppers who naturally varied in their levels of idea shopping. As in 
Study 3a, we manipulated the level of inspirational content by selectively displaying recipe suggestions, and we measured each participant's level of idea shopping. We again expected that participants with a high level of idea shopping would feel more inspired by an in-store promotion with high inspirational content than with low inspirational content. For participants with a low level of idea shopping, we anticipated an attenuated effect of inspirational content on customer inspiration. In order to investigate the hypothesized interaction, this study used a one-factorial (inspirational content: high vs. low) between-subject design, crossed with a continuous measure for idea shopping.

Participants and procedure. The 121 participants (61\% female, median age 54) in this study were shoppers who visited the local store of a national grocery chain on one of two consecutive Saturdays. In collaboration with the store management, we displayed an in-store promotion for 17 selected organic products. In the low-inspirational content condition, the in-store promotion featured only the selected organic products and promotional material that displayed the logo of the organic product line. In contrast, the high-inspirational content condition (which was featured in the same store a week after the low-inspirational condition) additionally displayed three recipes that used the featured products as ingredients (i.e., recipes for soup, a main course, and a dessert) and provided promotional material highlighting these three recipes. The types of products displayed, their number, and their arrangement were held constant between conditions. ${ }^{4}$ Soon after shoppers had passed the product display, they were approached by a trained student who was blind to our hypotheses, and were asked to complete a questionnaire that included our measures for customer inspiration and related constructs. All scales showed good psychometric properties (for further details, see the Web Appendix). Finally, we also measured purchase 
likelihood by observing whether participants added at least one of the products from the organic product display to their shopping baskets.

Results. To begin, we note that our findings replicate results from the previous study regarding experimental validity (see Table 4). In order to extend the predictive validity of customer inspiration, we analyzed its ability to improve the prediction of the likelihood of purchasing at least one of the products on display. As in Study 3a, we used hierarchical regressions to analyze our data (see Table 5). Because the choice to purchase one of the products is a binary outcome, we specified a logistic regression that assumes a binomial distribution of the dependent variable. The inclusion of the two customer inspiration states significantly improved the predictions of purchase likelihood (Nagelkerke's $\mathrm{R}^{2}=.45$ vs $.51 ; \chi^{2}(2)=7.50, p<.05$ ). Inspection of the regression coefficient revealed that the purchase likelihood was predicted by the inspired-to component of customer inspiration $\left(\mathrm{B}_{\mathrm{To}}=.43, \mathrm{SE}=.21, p<.05\right)$, in line with our results from Study 3a. Spotlight analysis revealed that $64 \%$ of participants who were strongly inspired to act $($ mean +1 S.D. $=5.47)$ purchased at least one of the products, while participants who were less inspired to act (mean - 1 S.D. $=1.95$ ) had a purchase likelihood of only $28 \%$. Together, these results replicate the tendency of our findings from Study 3a, and further support the experimental and predictive validity of the proposed customer inspiration scale.

\section{Study 4: Generalizability and Boundary Condition}

The goal of Study 4 was to explore the generalizability of customer inspiration and to introduce a boundary condition in line with our conceptualization. We first sought to establish generalizability by introducing a new manipulation to elicit inspiration. While our previous studies relied on participant recall of episodes of inspiration (Studies 1 and 2) or on exposure to inspirational content in the form of recipe suggestions (Studies 3a and 3b), Study 4 implements a 
more direct manipulation by appealing to customers' imagination. Using such imagery appealsurging consumers to imagine the product experience-is a widespread practice in marketing that has been shown to have powerful effects on attitudes and behavioral intentions (Petrova and Cialdini 2005). Imagery appeals stimulate an imagery processing style that increases both the quantity and the vividness of mental images, and facilitates the reception of new ideas (Bone and Ellen 1992; MacInnis and Price 1987). Because reception of new ideas, broadening of mental horizons, and stimulation of a person's imagination characterize being inspired by something, we hypothesize that imagery appeals (vs. lack of imagery appeals) increase customer inspiration.

Our second goal was to explore a theoretical boundary condition for inspiration. In line with recent conceptualizations of general inspiration (Jones, Dodd, and Gruber 2014; Thrash, Elliot, et al. 2010; Thrash et al. 2016), we posit that customer inspiration involves an approach motivation rather than an avoidance motivation. Furthermore, prior literature provides evidence that the frequency and intensity of general inspiration correlate with measures for the behavioral activation system, but not with measures for the behavioral inhibition system (Thrash and Elliot 2003). Finally, Thrash et al. (2010) found that individuals with a strong approach temperament tend to be inspired in response to creative insight, whereas individuals with a weak approach temperament report feeling a lack of inspiration in spite of their insight. We therefore hypothesize that imagery appeals have a positive effect on customer inspiration only for approach-framed advertisements, but have no effect for avoidance-framed advertisements.

Finally, in order to add generalizability, we changed the purchase context from a rather utilitarian setting (i.e., grocery shopping) to a more hedonic context. To test the hypothesized interaction, we designed a 2 (imagery appeal: high vs. low) x 2 (motivation: approach vs. avoid) between-subjects experiment in the context of a vacation advertisement. 
Participants and procedure. As a basis for manipulating imagery appeal and the type of motivation, we created four versions of a print advertisement for a vacation in Rome. We adopted stimuli presented by Petrova and Cialdini (2005, Study 2) to manipulate the ads' imagery appeal and ease of imagery processing. The high imagery appeal versions included phrases inviting consumers to imagine their experience at the advertised destination, while the other versions did not contain such imagery appeals. Further, the low imagery appeal versions contained less vivid descriptions of the activities and had slightly blurred background pictures to impede imagery processing.

In order to manipulate the type of motivation, we adapted a stimulus design from Zhu and Meyers-Levy (2007, Experiment 2). In the approach motivation versions, the copy text encouraged approach goals ("Travel to Rome"; "Capture your opportunity to visit Rome this summer"), while the other versions encouraged avoidance goals ("Escape to Rome"; "Don't let your opportunity to visit Rome this summer slip by").

We recruited 253 U.S.-consumers (53\% female, median age 32) from an online panel to participate in this study. Upon starting the study, participants were randomly assigned to one of the four experimental conditions and were then exposed to the associated version of our experimental travel advertisement. After reviewing the advertisement, participants completed a questionnaire that included measures of customer inspiration, general inspiration, related constructs, attitudes, and purchase intentions.

Measures. Customer inspiration was measured with the proposed 10-item scale. A CFA with the two-component model of customer inspiration showed an acceptable model fit (CFI $=.96$, $\mathrm{TLI}=.95, \mathrm{RMSEA}=.12, \mathrm{SRMR}=.041)$ and high item loadings $($ Table 2, column Study 4$)$. As before, we included measures for related marketing constructs and for general inspiration. All 
scales had high reliabilities and item loadings (see the Web Appendix for further details). Finally, participants also responded to five items to assess their attitude toward the advertisement $(\alpha=.97)$ and four items to measure their intention to purchase the advertised travel $(\alpha=.86)$, which were adapted from Petrova and Cialdini (2005).

In support of nomological validity, the inspired-by and inspired-to components of customer inspiration correlated significantly with their related constructs, with correlation coefficients ranging from .19 to .73 (Table 3, column Study 4). Furthermore, both customer inspiration states also correlated highly with general inspiration state $\left(\mathrm{r}_{\mathrm{by}}=.75, \mathrm{r}_{\mathrm{to}}=.63, p_{\mathrm{s}}<.001\right)$, indicating convergent validity. For all constructs, the square roots of the AVEs were larger than the correlations with any other constructs, and combining any construct with either inspired-by or inspired-to significantly decreased the overall model fit $\left(\Delta \chi^{2}(7)>136.97, p s<.001\right)$, supporting discriminant validity.

Effects on inspired-by. In order to test the proposed effect of imagery appeals and avoidance motivation as a boundary condition, we submitted the scores for inspired-by to a 2 (imagery appeal: high vs. low) x 2 (motivation: approach vs. avoid) ANOVA. As expected, we found a significant interaction effect on the inspired-by component between imagery appeal and type of motivation $(\mathrm{F}(1,249)=9.01, p<.01)$. No other effects were significant. Planned contrasts revealed a positive effect of imagery appeal on inspired-by for advertisements that featured approach goals $\left(\mathrm{M}_{\text {High-appeal }}=4.95, \mathrm{M}_{\text {Low-appeal }}=4.21, \mathrm{t}(249)=3.26, p<.01\right)$. In contrast, there was no significant effect for advertisements that featured avoidance goals $\left(\mathrm{M}_{\text {High-appeal }}=4.52\right.$, MLow-Appeal $=4.75, \mathrm{t}(249)=.99, p=.32)$, indicating the expected boundary condition.

Effects on inspired-to. As before, we tested a mediated moderation to account for the inspired-to component of inspiration. A mediation analysis using a bootstrapping procedure with 
1,000 samples revealed a significant indirect effect of imaginary appeal on inspired-to via inspired-by for the approach motivation conditions $\left(\mathrm{B}_{\text {Approach }}=.64,95 \% \mathrm{CI}=[.26,1.01], p<\right.$ $.001)$, but not for the avoidance motivation conditions $\left(\mathrm{B}_{\mathrm{Avoid}}=-.19,95 \% \mathrm{CI}=[-.58, .18], p=\right.$ .35). As reported in Table 4, there were no remaining direct effects, which supports a fully mediated moderation hypothesis of customer inspiration.

Predictive validity. We assessed the ability of customer inspiration to predict outcomes beyond the effects of related marketing constructs and general inspiration. A MANCOVA revealed significant effects of inspired-by $(\mathrm{V}=.07, \mathrm{~F}(2,243)=8.46, p<.001)$ and of inspired-to $(\mathrm{V}=.06, \mathrm{~F}(2,243)=7.12, p<.001)$ on attitudes toward the advertisement and on purchase intentions. Follow-up hierarchical regressions confirmed that the inclusion of the two customer inspiration states significantly improved the predictions of customers' attitudes and purchase intentions ( $p s<.001$, see Table 5). Inspection of the regression coefficients revealed that inspired-by significantly predicted attitudes toward the offer $\left(\mathrm{B}_{\mathrm{By}}=.34, \mathrm{SE}=.08, p<.001\right)$ and marginally predicted purchase intentions $\left(\mathrm{B}_{\mathrm{By}}=.16, \mathrm{SE}=.09, p=.08\right)$. Purchase intentions were also predicted significantly by the inspired-to component $\left(\mathrm{B}_{\mathrm{To}}=.19, \mathrm{SE}=.05, p<.001\right)$. This provides further indication that inspired-by may relate more to the deliberation phase, while inspired-to relates to the implementation phase (see Study 3a). Collectively, our results further support the reliability and validity of the proposed customer inspiration scale.

\section{General Discussion}

Implications for Marketing Theory 
Firms are increasingly exploring ways to develop and market solutions and ideas rather than products or services and to provide information that customers want to receive or even seek out (Marketing Science Institute 2016). In this research, we draw attention to inspiration as an understudied construct in marketing research that holds the potential to support managers in promoting new ideas that increase demand, foster exploration behavior, and strengthen customer loyalty. We define customer inspiration as a customer's temporary motivational state that facilitates the transition from the reception of a marketing-induced idea to the intrinsic pursuit of a consumption-related goal. As such, customer inspiration holds a unique position at the very beginning of the customer journey (Lemon and Verhoef 2016) that links the activating reception of a new idea with the intention to pursue a consumption-related goal. Due to an accelerated lifestyle and the non-stop availability of purchase options that shortens the customer journey, this moment of inspiration is becoming increasingly important from a marketing perspective.

Based on our theoretical definition of customer inspiration, we develop and validate a tenitem, two-factor scale to measure customer inspiration (see Table 2). Empirical results find consistently high convergent and discriminant validity of the scale, and show its unique position in a nomological network of related marketing constructs. Finally, we present evidence for the experimental and predictive validity of the proposed construct — under laboratory conditions as well as in the field. We conclude that the scale satisfies all criteria for newly developed construct measures, and has the potential to add a new perspective to marketing theory.

This paper offers a first link between two literature streams - the psychological inspiration literature and marketing literature — by introducing a contextualized conceptualization of inspiration in marketing that is compatible with recent conceptualizations of general inspiration. 
In this way, we want to spark a lively exchange of ideas across these two disciplines, and open up a new field of study for marketing and psychology scholars alike.

\section{Implications for the Practice of Marketing}

Customer inspiration has the potential to change the strategies that marketing managers use to increase demand, exploration behavior and, ultimately, customer loyalty. We find substantial evidence for inspiration leading to exploration behavior (Study 3a) and greater purchase intention (Studies 3a, 3b, and 4). Inspiration, thereby, suggests a new type of strategy for creating demand and opportunity to promote high-margin products. For instance, the New York-based retailer Story embraces an inspiration-type business model by building its entire merchandise and store layout on specific themes that change every few weeks like an art gallery (Harris 2014). Unlike other - and essentially backward-looking - marketing metrics such as satisfaction, customer inspiration is thus redirecting managerial attention toward thinking about exposing customers to new and surprising ideas, and offering a new perspective for marketing managers.

Furthermore, inspiration could serve as a means for increasing brand attachment and strengthening customer relationships. We find evidence that customer inspiration correlates with attitudinal consequences such as loyalty and satisfaction (Studies 2, 3a, 3b, and 4). While the moment of inspiration is a temporary, "hot" state that peaks quickly and vanishes afterward, the experience may thus result in higher repurchase intentions and positive word-of-mouth that increase customer lifetime value and create positive long-term impact for a company.

With regard to the drivers of customer inspiration, our studies identify two ways for firms to elicit inspiration. First, firms may inspire customers by presenting existing products in new or unexpected combinations. For instance, presenting inspirational content in the form of recipe suggestions alongside grocery products can inspire customers, even in utilitarian purchase 
contexts (Studies 3a and 3b). Similarly, fashion companies may present their products in combination to show customers how to create new outfits, and home furnishings retailers can display their products in fully-furnished rooms rather than as separate furniture items. Moreover, we find that such manipulations have the strongest effects for customers who actively search for new ideas (i.e., have an idea shopping motive.). Second, our results suggest that imagery processing may foster inspiration (Study 4), thus encouraging firms to use engaging imagery. New technologies such as virtual and augmented reality, digital signage, and online tools (e.g., Pinterest's visual search) could support the creation of visual content to inspire customers.

Summing up the managerial insights, we note that a valid and reliable measure of customer inspiration, and the realization that such measures are important to outcomes in practice, may serve as the foundation for an evidence-based marketing of ideas.

\section{Avenues for Future Research}

While our study has identified several key drivers of inspiration, we acknowledge that many more sources of customer inspiration exist and deserve further exploration. Our proposed tenitem scale offers the flexibility to measure customer inspiration independently from its source, and thus presents a universal in-situ measure for tapping into this new field of research. Because it is intentionally designed as a parsimonious measure, the scale would be easy to administer within existing surveys. As a valid and reliable tool, the scale can, therefore, create a basis for future studies on customer inspiration in the customer journey.

Because a comprehensive assessment of the wider nomological network was beyond the scope of this study, a productive area for future investigation is the relationship between customer inspiration and established marketing constructs. For example, recent research has discussed the importance of customer engagement as a construct for measuring and managing a 
customer's value addition to the firm (Brodie et al. 2011; Pansari and Kumar 2016). Customer inspiration may foster customer engagement by creating strong positive attitudes, motivations, and loyalty. In line with recent research on the writer-reader contagion of inspiration (Thrash et al. 2016), inspired customers may also pass their inspiration on to other customers by creating and sharing content (e.g., viral videos, social media posts).

Future research could also investigate alternative paths between constructs in the nomological network. For example, while our results suggest that customer inspiration fosters positive affect, it also correlates with impulse purchases, which can trigger negative emotions (Rook and Fisher 1995). Furthermore, because customer inspiration is related to increased purchase likelihood, as well as to satisfaction and loyalty intentions, future research could investigate whether purchase behavior mediates the effect of customer inspiration on satisfaction and loyalty. Clearly, more research is needed on the role of customer inspiration in marketing.

\section{Conclusion}

The intent to inspire customers should lie at the heart of marketing, yet inspiration has received little attention in prior research. By conceptualizing customer inspiration and by developing a sound measure for this new construct, our study establishes a first step toward firmly embedding inspiration in management practice. We hope that our work-similar to the research on satisfaction in the $1980 \mathrm{~s}$ - stimulates academic research and offers firms new approaches to develop and market solutions that improve everyday shopping experiences for customers, and that will eventually lead to longer and more valuable customer relationships. 


\section{Footnotes}

${ }^{1}$ In the retailing contexts of groceries $(n=101)$, fashion $(n=120)$, sports $(n=204)$, consumer electronics $(n=226)$, and furniture $(n=267)$, trained students randomly approached shoppers and asked them to (1) name spontaneous associations with inspiration and (2) describe an inspiring customer journey.

${ }^{2}$ The resulting item scores revealed considerable diversity in experts' evaluations (intraclass correlation $($ ICC $)(2,10)=.58)$. Interestingly, there was general agreement among academic experts $(\operatorname{ICC}(2,5)=.70)$, but substantial disagreement among managerial experts $(\operatorname{ICC}(2,5)=$ .19). This may indicate differences in the prevalent perspectives on customer inspiration in various consumer industries. In order to account for these differences, we opted for a comparatively conservative elimination criterion.

${ }^{3}$ Note that the traditional .05 cutoff value for RMSEA is less preferable when applied to models derived from small $(\mathrm{N}<250)$ and possibly moderate $(\mathrm{N}<500)$ sample sizes, since they tend to over-reject appropriate models (Hu and Bentler 1999).

${ }^{4}$ Due to practical constraints, it was not possible to counterbalance the two conditions. Therefore, we made the decision to place the high inspirational content condition second, so that any effect due to the mere novelty of the presentation itself would attenuate rather than confound the expected effect of our manipulation on customer inspiration. Furthermore, as none of the participants on the second Saturday indicated that they had visited the store on the previous Saturday, mere exposure is unlikely to account for the observed effects. 


\section{References}

Aaker, Jennifer L. (1997), “Dimensions of Brand Personality,” Journal of Marketing Research, $34(3), 347-56$.

Ajzen, Icek (1987), “Attitudes, Traits, and Actions: Dispositional Prediction of Behavior in Personality and Social Psychology," in Advances in Experimental Social Psychology, Leonard Berkowitz, ed., Academic Press, 1-63.

American Marketing Association (2013), “Definition of Marketing,” (accessed May 16, 2017), [available at https://www.ama.org/AboutAMA/Pages/Definition-of-Marketing.aspx].

Arnold, Mark J. and Kristy E. Reynolds (2003), "Hedonic Shopping Motivations," Journal of Retailing, 79 (2), 77-95.

Arnould, Eric J. and Linda L. Price (1993), "River Magic: Extraordinary Experience and the Extended Service Encounter,” Journal of Consumer Research, 20 (1), 24-45.

Aslam, Salman (2017), "Pinterest by the Numbers (2017): Stats, Demographics \& Fun Facts," omnicoreagency.com.

Bagozzi, Richard P. and Youjae Yi (1988), "On the Evaluation of Structural Equation Models," Journal of the Academy of Marketing Science, 16 (1), 74-94. 
Barnes, Nora Ganim and Ava M. Lescault (2014), "Millennials Drive Social Commerce: Turning Their Likes, Follows or Pins Into a Sale," Center for Marketing Research University of Massachusetts Dartmouth.

Bearden, William O., Richard G. Netemeyer, and Jesse E. Teel (1989), “Measurement of Consumer Susceptibility to Interpersonal Influence,” Journal of Consumer Research, 15 (4), $473-81$

Bone, Paula Fitzgerald and Pam Scholder Ellen (1992), "The Generation and Consequences of Communication-Evoked Imagery,” Journal of Consumer Research, 19 (1), 93-104.

Brodie, Roderick J., Linda D. Hollebeek, Biljana Jurić, and Ana Ilić (2011), “Customer Engagement: Conceptual Domain, Fundamental Propositions, and Implications for Research,” Journal of Service Research, 14 (3), 252-71.

Burnkrant, Robert E. and Thomas J. Page (1982), “An Examination of the Convergent, Discriminant, and Predictive Validity of Fishbein's Behavioral Intention Model,” Journal of Marketing Research, 19 (4), 550-61.

Celsi, Richard L., Randall L. Rose, and Thomas W. Leigh (1993), “An Exploration of High-Risk Leisure Consumption Through Skydiving,” Journal of Consumer Research, 20 (1), 1-23. 
Churchill, Gilbert A. (1979), “A Paradigm for Developing Better Measures of Marketing Constructs,” Journal of Marketing Research, 16 (1), 64-73.

Edwards, Jeffrey R. and Lisa Schurer Lambert (2007), “Methods for Integrating Moderation and Mediation: A General Analytical Framework Using Moderated Path Analysis," Psychological Methods, 12 (1), 1-22.

Elliot, Andrew J. and Todd M. Thrash (2002), “Approach-Avoidance Motivation in Personality: Approach and Avoidance Temperaments and Goals," Journal of Personality and Social Psychology, 82 (5), 804-18.

Evanschitzky, Heiner, Oliver Emrich, Vinita Sangtani, Anna-Lena Ackfeldt, Kristy E. Reynolds, and Mark J. Arnold (2014), "Hedonic Shopping Motivations in Collectivistic and Individualistic Consumer Cultures," International Journal of Research in Marketing, 3 (31), 335-338.

Finn, Adam (2005), "Reassessing the Foundations of Customer Delight," Journal of Service Research, 8 (2), 103-16.

Fornell, Claes and David F. Larcker (1981), "Evaluating Structural Equation Models with Unobservable Variables and Measurement Error," Journal of Marketing Research, 18 (1), 3950. 
Gerbing, David W. and James C. Anderson (1988), “An Updated Paradigm for Scale Development Incorporating Unidimensionality and Its Assessment,” Journal of Marketing Research, 25 (2), 186-92.

Goldsmith, Ronald E. and Charles F. Hofacker (1991), "Measuring Consumer Innovativeness," Journal of the Academy of Marketing Science, 19 (3), 209-21.

Gollwitzer, Peter M. (1990), “Action Phases and Mindsets," in Handbook of motivation and cognition: Foundations of social behavior, E. T. Higgins and R. M. Sorrentino, eds., New York, NY, US: Guilford Press, 53-92.

Harris, Elizabeth A. (2014), “A Store With Media in Mind,” The New York Times.

Hart, Tobin (1998), "Inspiration: Exploring the Experience and its Meaning," Journal of Humanistic Psychology, 38 (3), 7-35.

Hu, Li-tze and Peter M. Bentler (1999), “Cutoff Criteria for Fit Indexes in Covariance Structure Analysis: Conventional Criteria Versus New Alternatives," Structural Equation Modeling: A Multidisciplinary Journal, 6, 1-55.

Hymer, Sharon (1990), “On Inspiration,” Psychotherapy Patient, 6 (3-4), 17-38. 
Jones, Steven, Alyson Dodd, and June Gruber (2014), "Development and Validation of a New Multidimensional Measure of Inspiration: Associations with Risk for Bipolar Disorder," Plos One, 9 (3), e91669.

Kassarjian, Harold H. (1971), "Personality and Consumer Behavior: A Review," Journal of Marketing Research, 8 (4), 409-18.

Kozinets, Robert V. (2002), "Can Consumers Escape the Market? Emancipatory Illuminations from Burning Man,” Journal of Consumer Research, 29 (1), 20-38.

Lee, Leonard and Dan Ariely (2006), "Shopping Goals, Goal Concreteness, and Conditional Promotions," Journal of Consumer Research, 33 (1), 60-70.

— and Tim M. Böttger (forthcoming), "The Therapeutic Utility of Shopping: Retail Therapy, Emotion Regulation, and Well-Being," in The Routledge Companion to Consumer Behavior, T. Lowrey and M. Solomon, eds., Abingdon-on-Thames, UK: Routledge, in press.

Lemon, Katherine N. and Peter C. Verhoef (2016), "Understanding Customer Experience Throughout the Customer Journey," Journal of Marketing, 80 (6), 69-96.

Lewin, Kurt (1935), A Dynamic Theory of Personality: Selected Papers, McGraw-Hill publications in psychology, New York, NY, US: McGraw-Hill. 
Liang, Jianping, Zengxiang Chen, and Jing Lei (2016), "Inspire Me to Donate: The Use of Strength Emotion in Donation Appeals," Journal of Consumer Psychology, 26 (2), 283-88.

Lockwood, Penelope and Ziva Kunda (1999), “Increasing the Salience of One's Best Selves Can Undermine Inspiration by Outstanding Role Models," Journal of Personality and Social Psychology, 76 (2), 214-28.

MacInnis, Deborah J. and Linda L. Price (1987), "The Role of Imagery in Information Processing: Review and Extensions," Journal of Consumer Research, 13 (4), 473-91.

Marketing Science Institute (2016), Research Priorities 2016-2018, Cambridge, MA, US: Marketing Science Institute.

Nenkov, Gergana Y., J. Jeffrey Inman, and John Hulland (2008), "Considering the Future: The Conceptualization and Measurement of Elaboration on Potential Outcomes," Journal of Consumer Research, 35 (1), 126-41.

Oleynick, Victoria C., Todd M. Thrash, Michael C. LeFew, Emil G. Moldovan, and Paul D. Kieffaber (2014), "The Scientific Study of Inspiration in the Creative Process: Challenges and Opportunities," Frontiers in Human Neuroscience, 8.

Oliver, Richard L, Roland T Rust, and Sajeev Varki (1997), “Customer Delight: Foundations, Findings, and Managerial Insight,” Journal of Retailing, 73 (3), 311-36. 
Pansari, Anita and V. Kumar (2016), "Customer Engagement: The Construct, Antecedents, and Consequences," Journal of the Academy of Marketing Science, 1-18.

Park, C. Whan, Andreas B. Eisingerich, and Jason Whan Park (2013), “Attachment-Aversion (AA) Model of Customer-brand Relationships," Journal of Consumer Psychology, 23 (2), 22948.

Petrova, Petia K. and Robert B. Cialdini (2005), "Fluency of Consumption Imagery and the Backfire Effects of Imagery Appeals,” Journal of Consumer Research, 32 (3), 442-52.

Pinterest (2017), “Success Stories,” Pinterest for Business - Success Stories, (accessed January 27, 2017), [available at https://business.pinterest.com/en/success-stories].

Richins, Marsha L. (2004), “The Material Values Scale: Measurement Properties and Development of a Short Form,” Journal of Consumer Research, 31 (1), 209-19.

Rook, Dennis W. and Robert J. Fisher (1995), “Normative Influences on Impulsive Buying Behavior," Journal of Consumer Research, 22 (3), 305-13.

Ryan, R M and E L Deci (2000), "Self-determination Theory and the Facilitation of Intrinsic Motivation, Social Development, and Well-being," The American Psychologist, 55 (1), 68-78. 
Schouten, John W., James H. McAlexander, and Harold F. Koenig (2007), “Transcendent Customer Experience and Brand Community," Journal of the Academy of Marketing Science, 35 (3), 357-68.

Silver, Hayley (2012), “Online Consumer Pulse Pinterest vs. Facebook: Which Social Sharing Site Wins at Shopping Engagement?," Bizrate Insights.

Stanton, Jeffrey M., Evan F. Sinar, William K. Balzer, and Patricia C. Smith (2002), "Issues and Strategies for Reducing the Length of Self-Report Scales," Personnel Psychology, 55 (1), 16794.

Steiger, James H. (1980), "Tests for Comparing Elements of a Correlation Matrix," Psychological Bulletin, 87 (2), 245-51.

Thrash, Todd M. and Andrew J. Elliot (2003), "Inspiration as a Psychological Construct," Journal of Personality and Social Psychology, 84 (4), 871-89.

$\longrightarrow$ and (2004), "Inspiration: Core Characteristics, Component Processes, Antecedents, and Function,” Journal of Personality and Social Psychology, 87 (6), 957-73.

,-- Laura A. Maruskin, and Scott E. Cassidy (2010), "Inspiration and the Promotion of Well-Being: Tests of Causality and Mediation," Journal of Personality and Social Psychology, 98 (3), 488-506. 
—, Laura A. Maruskin, Scott E. Cassidy, James W. Fryer, and Richard M. Ryan (2010), "Mediating Between the Muse and the Masses: Inspiration and the Actualization of Creative Ideas,” Journal of Personality and Social Psychology, 98 (3), 469-87.

$\longrightarrow, \ldots$, Emil G. Moldovan, Victoria C. Oleynick, and Will C. Belzak (2016), "WriterReader Contagion of Inspiration and Related States: Conditional Process Analyses Within a Cross-Classified Writer $\times$ Reader Framework.," Journal of Personality and Social Psychology, 1-26.

—_, Emil G. Moldovan, Victoria C. Oleynick, and Laura A. Maruskin (2014), “The Psychology of Inspiration," Social and Personality Psychology Compass, 8 (9), 495-510.

Tian, Kelly Tepper, William O. Bearden, and Gary L. Hunter (2001), “Consumer’s Need for Uniqueness: Scale Development and Validation,” Journal of Consumer Research, 28 (1), 50-66.

Zhu, Rui and Joan Meyers-Levy (2007), "Exploring the Cognitive Mechanism that Underlies Regulatory Focus Effects,” Journal of Consumer Research, 34 (1), 89-96. 
TABLE 1

\section{OVERVIEW OF EXISTING FRAMEWORKS FOR INSPIRATION}

\begin{tabular}{|c|c|c|c|c|}
\hline Framework & Focus of Framework & Nominal Definition & Parts Within Framework & Related Research \\
\hline $\begin{array}{l}\text { Tripartite } \\
\text { conceptualization } \\
\text { (Thrash and Elliot 2003) }\end{array}$ & $\begin{array}{l}\text { Core characteristics } \\
\text { of inspiration as a } \\
\text { trait and as a state }\end{array}$ & $\begin{array}{l}\text { Inspiration is conceptualized as both a trait } \\
\text { and a state because it is presumed to vary } \\
\text { both between and within individuals. (p. } 873 \text { ) } \\
\text { Inspiration is characterized by evocation, } \\
\text { motivation, and transcendence. (p. } 885 \text { ) }\end{array}$ & $\begin{array}{l}\text { Evocation: feeling overtaken, } \\
\text { uncontrol, attraction from the } \\
\text { object, openness } \\
\text { - Transcendence: positivity, } \\
\text { enhancement, clarity } \\
\text { - Motivation: activation, energy }\end{array}$ & $\begin{array}{l}\text { - Milyavskaya et al. } \\
\text { (2012) } \\
\text { - Jones et al. (2014) }\end{array}$ \\
\hline $\begin{array}{l}\text { Component process } \\
\text { conceptualization } \\
\text { (Thrash and Elliot 2004) }\end{array}$ & $\begin{array}{l}\text { Distinct components } \\
\text { that together } \\
\text { compose an episode } \\
\text { of inspiration }\end{array}$ & $\begin{array}{l}\text { Inspiration is a hybrid construct that emerges } \\
\text { from the juxtaposition of two component } \\
\text { processes, one involving an appreciation of } \\
\text { and accommodation to an evocative object } \\
\text { (hereafter referred to as being inspired by), } \\
\text { the other involving motivation to extend the } \\
\text { qualities exemplified in the evocative object } \\
\text { (hereafter referred to as being inspired to). } \\
\text { (p. 958) }\end{array}$ & $\begin{array}{l}\text { - Inspired by: associated with } \\
\text { Transcendence and denial of } \\
\text { responsibility (Evocation) } \\
\text { - Inspired to: associated with } \\
\text { appetitive Motivation }\end{array}$ & $\begin{array}{l}\text { - Thrash, Elliot, et al. } \\
\text { (2010) } \\
\text { - Stephan et al. (2015) } \\
\text { - Liang et al. (2016) }\end{array}$ \\
\hline $\begin{array}{l}\text { Transmission model } \\
\text { (Thrash, Maruskin } \\
\text { et al. 2010) }\end{array}$ & $\begin{array}{l}\text { Purpose or function } \\
\text { of inspiration in the } \\
\text { creative process }\end{array}$ & $\begin{array}{l}\text { Inspiration to create is a motivational state } \\
\text { that is evoked in response to getting a } \\
\text { creative idea and that compels the individual } \\
\text { to transform the creative idea into a creative } \\
\text { product. (p. } 470 \text { ) }\end{array}$ & $\begin{array}{l}\text { - Sources of inspiration (i.e., } \\
\text { creative idea) as antecedent } \\
\text { - Inspiration as a mediating state } \\
\text { - Actualization of the idea as a } \\
\text { consequence }\end{array}$ & $\begin{array}{l}\text { - Oleynick et al. (2014) } \\
\text { - Thrash et al. (2014) } \\
\text { - Figgins et al. (2016) } \\
\text { - Thrash et al. (2016) }\end{array}$ \\
\hline
\end{tabular}

Notes: A more extensive literature review is available in the Web Appendix. 
TABLE 2

\section{CUSTOMER INSPIRATION SCALE: CONFIRMATORY FACTOR ANALYSIS AND ITEM LOADINGS}

\begin{tabular}{|c|c|c|c|c|c|}
\hline Item & Study 1 & Study 2 & Study $3 \mathrm{a}$ & Study $3 b$ & Study 4 \\
\hline Inspired by $(C R ; A V E)$ & $(.89 ; .62)$ & $(.87 ; .58)$ & $(.92 ; .68)$ & $(.89 ; .62)$ & $(.90 ; .64)$ \\
\hline My imagination was stimulated. & .86 & .78 & .77 & .84 & .75 \\
\hline I was intrigued by a new idea. & .81 & .79 & .83 & .79 & .82 \\
\hline I unexpectedly and spontaneously got new ideas. & .80 & .78 & .87 & .87 & .82 \\
\hline My horizon was broadened. & .75 & .78 & .88 & .75 & .84 \\
\hline I discovered something new. & .72 & .67 & .80 & .67 & .77 \\
\hline Inspired to(CR; AVE) & $(.92 ; .70)$ & $(.93 ; .71)$ & $(.97 ; .85)$ & $(.96 ; .84)$ & $(.98 ; .91)$ \\
\hline I was inspired to buy something. & .86 & .79 & .91 & .86 & .96 \\
\hline I felt a desire to buy something. & .84 & .89 & .93 & .93 & .96 \\
\hline My interest to buy something was increased. & .84 & .87 & .94 & .95 & .94 \\
\hline I was motivated to buy something. & .83 & .78 & .92 & .95 & .96 \\
\hline I felt an urge to buy something. & .79 & .90 & .90 & .89 & .95 \\
\hline Observations & 257 & 425 & 230 & 121 & 253 \\
\hline Factor correlation & .76 & .57 & .75 & .62 & .64 \\
\hline$\chi^{2}(34)$ & 51.01 & 182.50 & 147.48 & 67.96 & 158.43 \\
\hline Comparative fit index & .99 & .95 & .95 & .97 & .96 \\
\hline Tucker-Lewis index & .99 & .93 & .94 & .96 & .95 \\
\hline Root mean square error of approximation & .04 & .10 & .12 & .09 & .12 \\
\hline Standardized root mean square residual & .029 & .045 & .040 & .033 & .041 \\
\hline
\end{tabular}

Standardized root mean square residual

Notes: CR Composite reliability; AVE Average variance extracted

All factor loadings and factor correlations are significant at $p<.001$

A list of the initial 18-item long scale is available in the Web Appendix. 
TABLE 3

NOMOLOGICAL VALIDITY: CORRELATIONS COEFFICIENTS FOR INSPIRED-BY AND INSPIRED-TO AND RELATED MARKETING CONSTRUCTS

\begin{tabular}{|c|c|c|c|c|c|c|c|c|c|c|c|c|c|}
\hline \multirow[b]{2}{*}{ Construct } & \multirow[b]{2}{*}{ Conceptual Category } & \multicolumn{3}{|c|}{ Study 2} & \multicolumn{3}{|c|}{ Study $3 \mathrm{a}$} & \multicolumn{3}{|c|}{ Study $3 b$} & \multicolumn{3}{|c|}{ Study 4} \\
\hline & & $\begin{array}{c}\text { Insp. } \\
\text { by }\end{array}$ & & Insp. to & $\begin{array}{r}\text { Insp. } \\
\text { by }\end{array}$ & & Insp. to & $\begin{array}{r}\text { Insp. } \\
\text { by }\end{array}$ & & Insp. to & Insp. by & & Insp. to \\
\hline Idea shopping & Antecedent (individual) & $.28^{* * *}$ & & $.30^{* * *}$ & $.57^{* * *}$ & $>$ & $.48^{* * *}$ & $.44^{* * *}$ & & $.44^{* * *}$ & $.33^{* * *}$ & & $.37^{* * *}$ \\
\hline Impulse buying & Behavioral consequence & $.16^{* *}$ & $<$ & $.41^{* * *}$ & $.32^{* * *}$ & & $.34^{* * *}$ & $.32^{* * *}$ & & $.29^{* *}$ & $.19^{* * *}$ & $<$ & $.32^{* * *}$ \\
\hline Delight & Emotional consequence & $.57^{* * *}$ & $>$ & $.44^{* * *}$ & $.73^{* * *}$ & $>$ & $.59^{* * *}$ & $.62^{* * *}$ & $>$ & $.44^{* * *}$ & $.73^{* * *}$ & $>$ & $.59^{* * *}$ \\
\hline Positive affect & Emotional consequence & $.31^{* * *}$ & & $.26^{* * *}$ & $.65^{* * *}$ & $>$ & $.53^{* * *}$ & $.38^{* * *}$ & & $.43^{* * *}$ & $.63^{* * *}$ & $>$ & $.49^{* * *}$ \\
\hline $\begin{array}{l}\text { Transcendent customer } \\
\text { experience }\end{array}$ & Emotional consequence & $.54^{* * *}$ & $>$ & $.42^{* * *}$ & $.69^{* * *}$ & $>$ & $.53^{* * *}$ & $.51^{* * *}$ & & $.44^{* * *}$ & $.69^{* * *}$ & $>$ & $.58^{* * *}$ \\
\hline Customer satisfaction & Attitudinal consequence & $.22^{* * *}$ & & $.18^{* * *}$ & $.67^{* * *}$ & & $.64^{* * *}$ & $.31^{* * *}$ & & $.19^{*}$ & - & & - \\
\hline Loyalty intention & Attitudinal consequence & $.22^{* * *}$ & & $.19^{* * *}$ & $.73^{* * *}$ & & $.67^{* * *}$ & $.35^{* * *}$ & & $.25^{* *}$ & - & & - \\
\hline
\end{tabular}

${ }^{\dagger} p<.10 ;{ }^{*} p<.05 ;{ }^{* *} p<.01 ;{ }^{* * *} p<0.001$

Notes: Significant differences at $p<.05$ between correlations are indicated with $<$ and $>$. 
TABLE 4

EXPERIMENTAL VALIDITY: SIMPLE EFFECTS OF MANIPULATIONS ON STATES OF CUSTOMER INSPIRATION (MEDIATED MODERATION ANALYSIS)

\begin{tabular}{lcccc}
\hline \multirow{2}{*}{$\begin{array}{c}\text { Moderator } \\
\text { variable }\end{array}$} & $\begin{array}{c}\text { Effect on } \\
\text { Inspired-By }\end{array}$ & \multicolumn{3}{c}{ Effects on Inspired-To } \\
\cline { 4 - 5 } & & & & \\
\hline $\begin{array}{l}\text { Study 3a: Idea Shopping } \\
\text { High }\end{array}$ & $.93^{* * *}$ & $.69^{* *}$ & -.03 & $.66^{* *}$ \\
Low & .22 & .16 & -.23 & -.07 \\
Study 3b: Idea Shopping & & & & \\
High (Mean +1 SD) & $.80^{*}$ & $.47^{*}$ & -.26 & .22 \\
Low (Mean - 1 SD) & .32 & .19 & -.20 & -.01 \\
& & & & \\
Study 4: Motivation framing & & & & \\
Approach & $.74^{* *}$ & $.64^{* *}$ & -.11 & $.53^{\dagger}$ \\
Avoidance & -.23 & -.19 & -.04 & -.23 \\
\hline${ }^{\dagger} p<.10 ;{ }^{*} p<.05 ;{ }^{* *} p<.01 ;{ }^{* * *} p<0.001$ & & &
\end{tabular}


TABLE 5

PREDICTIVE VALIDITY: MANCOVA AND HIERARCHICAL REGRESSION RESULTS

\begin{tabular}{|c|c|c|c|c|c|c|c|c|c|}
\hline & \multicolumn{5}{|c|}{ Study $3 a$} & \multirow{2}{*}{$\begin{array}{c}\text { Study 3b } \\
\text { Purchase } \\
\text { likelihood } \\
\text { Binomial } \\
(6)\end{array}$} & \multicolumn{3}{|c|}{ Study 4} \\
\hline & $\begin{array}{l}\text { Overall effect } \\
\text { Study 3a } \\
\text { Pillai's trace } \\
\text { (1) }\end{array}$ & $\begin{array}{l}\text { Number of } \\
\text { clicks } \\
\text { Poisson } \\
(2)\end{array}$ & $\begin{array}{c}\text { Shopping } \\
\text { duration } \\
\text { Log-normal } \\
\text { (3) }\end{array}$ & $\begin{array}{l}\text { Products } \\
\text { viewed } \\
\text { Poisson } \\
(4) \\
\end{array}$ & $\begin{array}{c}\text { Purchase } \\
\text { intention } \\
\text { Normal } \\
(5) \\
\end{array}$ & & $\begin{array}{l}\text { Overall effect } \\
\text { Study } 4 \\
\text { Pillai's trace } \\
\text { (7) }\end{array}$ & $\begin{array}{c}\text { Normal } \\
(8)\end{array}$ & $\begin{array}{c}\text { Purchase } \\
\text { intention } \\
\text { Normal } \\
(9) \\
\end{array}$ \\
\hline \multicolumn{10}{|l|}{ Step 2} \\
\hline Inspired-By & $.06^{*}$ & $.11^{* * *}$ & $.26^{*}$ & .02 & $.25^{*}$ & .08 & $.07^{* * *}$ & $.34^{* * *}$ & $.16^{\dagger}$ \\
\hline Inspired-To & $.08^{* *}$ & $.05^{* * *}$ & .05 & $.11 *$ & $.30^{* * *}$ & $.43^{*}$ & $.06^{* * *}$ & -.001 & $.19^{* * *}$ \\
\hline General Inspiration & .003 & -.01 & .003 & -.03 & .05 & -- & $.03^{*}$ & $.12^{\dagger}$ & $.19^{*}$ \\
\hline Idea Shopping & $.05^{*}$ & $-.07^{* * *}$ & -.11 & .02 & $.15^{*}$ & .02 & .01 & -.01 & .09 \\
\hline Positive Affect & .02 & $.07^{* * *}$ & .13 & .04 & -.08 & $.42^{*}$ & $.04^{* *}$ & $.24^{* * *}$ & .03 \\
\hline TCE & $.06^{*}$ & $-.10^{* * *}$ & $-.26^{* *}$ & .006 & $.20^{*}$ & .17 & .01 & .01 & -.12 \\
\hline Delight & .01 & -.02 & -.06 & -.04 & .12 & -.20 & .01 & .02 & .12 \\
\hline Impulse Buying & .01 & $-.04^{* * *}$ & -.02 & -.004 & .02 & -.10 & $.01^{\dagger}$ & -.08 & -.08 \\
\hline \multicolumn{10}{|l|}{ Step 1} \\
\hline General Inspiration & .04 & $.03^{*}$ & .08 & .01 & $.22^{* *}$ & -- & $.09^{* * *}$ & $.22^{* * *}$ & $.31^{* * *}$ \\
\hline Idea Shopping & $.07^{* *}$ & $-.05^{* * *}$ & -.05 & .03 & $.23^{* * *}$ & .10 & .01 & -.01 & $.10^{\dagger}$ \\
\hline Positive Affect & .04 & $.11^{* * *}$ & $.21^{*}$ & .07 & .05 & $.42^{*}$ & $.05^{* *}$ & $.28^{* * *}$ & .05 \\
\hline TCE & $.05^{*}$ & $-.08^{* * *}$ & $-.22^{*}$ & .01 & $.23^{*}$ & .27 & .01 & .07 & -.04 \\
\hline Delight & .01 & .001 & -.03 & -.04 & .16 & -.05 & .02 & .08 & $.16^{\dagger}$ \\
\hline Impulse Buying & .01 & $-.04^{* * *}$ & -.02 & .001 & .03 & -.12 & .01 & $-.09^{\dagger}$ & -.05 \\
\hline \multicolumn{10}{|l|}{ Incremental Fit } \\
\hline $\mathrm{R}^{2}$ Step 1 & & $.59^{\mathrm{a}}$ & $.06^{\mathrm{a}}$ & $.03^{\mathrm{a}}$ & $.51^{\mathrm{a}}$ & $.45^{\mathrm{a}}$ & & $.39^{\mathrm{b}}$ & $.33^{\mathrm{b}}$ \\
\hline $\mathrm{R}^{2}$ Step 2 & & $.74^{\mathrm{a}}$ & $.10^{\mathrm{a}}$ & $.07^{\mathrm{a}}$ & $.57^{\mathrm{a}}$ & $.51^{\mathrm{a}}$ & & $.42^{\mathrm{b}}$ & $.37^{\mathrm{b}}$ \\
\hline$\Delta \mathrm{R}^{2}(\%$ of Step 2$)$ & & $.15(20 \%)$ & $.04(39 \%)$ & $.04(54 \%)$ & $.07(12 \%)$ & $.06(12 \%)$ & & $.03(8 \%)$ & $.04(12 \%)$ \\
\hline Test statistic & & $\begin{array}{c}\chi^{2}(2)= \\
96.38^{* * *}\end{array}$ & $\begin{array}{c}\chi^{2}(2)= \\
13.91^{*}\end{array}$ & $\begin{array}{c}\chi^{2}(2)= \\
7.91^{*}\end{array}$ & $\begin{array}{c}\chi^{2}(2)= \\
47.09^{* * *}\end{array}$ & $\begin{array}{c}\chi^{2}(2)= \\
7.50^{*}\end{array}$ & & $\begin{array}{c}\mathrm{F}(2,244)= \\
8.24^{* * *}\end{array}$ & $\begin{array}{c}\mathrm{F}(2,244)= \\
9.58^{* * *}\end{array}$ \\
\hline
\end{tabular}

a Nagelkerke's $\mathrm{R}^{2}$. b Adjusted ordinary least squares $\mathrm{R}^{2}$

Notes: Regression constants omitted. 
FIGURE 1

CONCEPTUAL FRAMEWORK OF CUSTOMER INSPIRATION AND RELATED MARKETING CONSTRUCTS

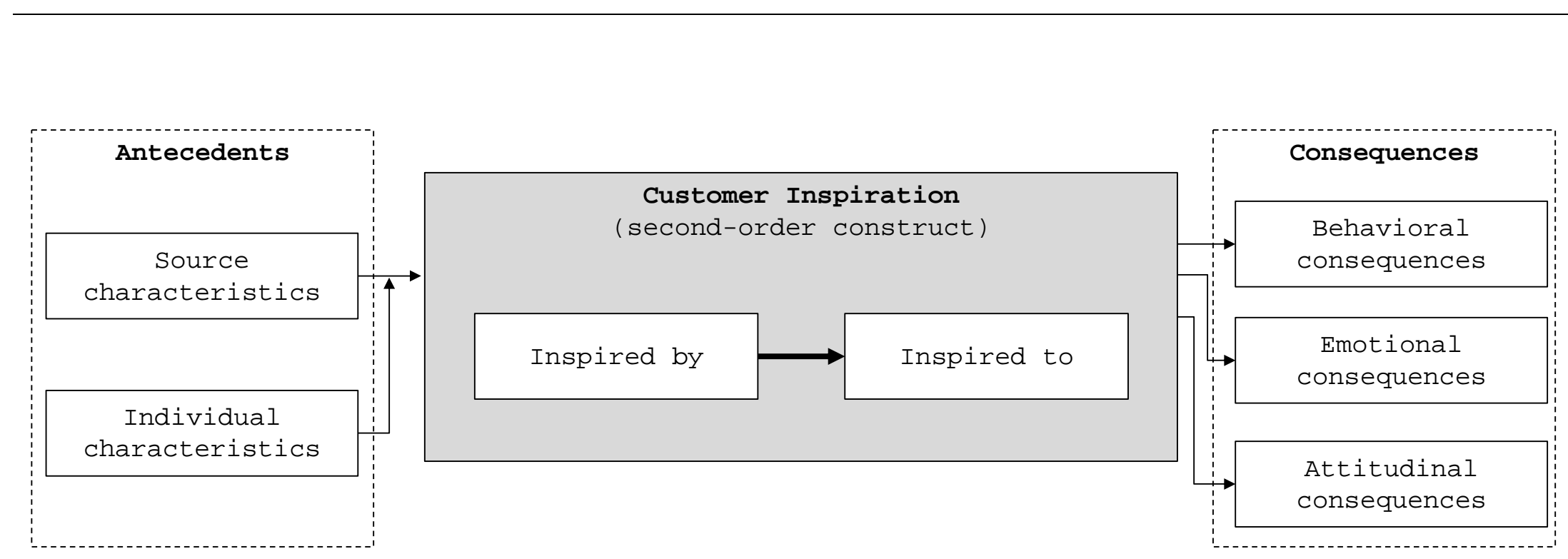

